\title{
Commentary: Don't get lost in the loop
}

\author{
Vito Domenico Bruno, MD, $\mathrm{PhD},{ }^{\mathrm{a}}$ and \\ Mustafa Zakkar, PhD, FRCS ${ }^{b}$
}

In the latest issue of the Journal, Morisaki and colleagues ${ }^{1}$ have presented an interesting paper that assesses the outcome of the loop technique in mitral valve (MV) repair using the intraoperative ink-dot marking test. The loop technique was originally described 20 years ago ${ }^{2}$ and consists in using premeasured expanded polytetrafluoroethylene loops. The authors have a long-standing experience with the loop technique and have already previously reported their series of 180 patients requiring this technique, ${ }^{3}$ with excellent results in terms of freedom from recurrence of mitral regurgitation and suggesting that this method is especially helpful for bileaflet prolapse. ${ }^{3}$

In the current paper, they report a larger number of procedures and describe an improvement of the technique using the ink-dot marking test, which involves the creation of a dotted line between the rough and the clear zones in the anterior leaflet and the center of the posterior leaflet. This improvement originated from the need of a more reliable way of intraoperative measurement of residual regurgitation: in fact, the commonly used saline test is not always reliable. Ink tests have been previously reported, ${ }^{4}$ but the authors of the current study have improved it further and with their ink-dot marking they have been able to achieve a less than mild residual regurgitation at discharge in $99.4 \%$ of the cases. These results are even more astonishing if we consider that this study includes posterior, anterior,

From ${ }^{\mathrm{a} B r i s t o l}$ Medical School - Translational Health Science, University of Bristol, Bristol; and ${ }^{\mathrm{b}}$ Department of Cardiovascular Sciences, University of Leicester, Clinical Sciences Wing, Glenfield General Hospital, Leicester, United Kingdom. Disclosures: The authors reported no conflicts of interest.

The Journal policy requires editors and reviewers to disclose conflicts of interest and to decline handling or reviewing manuscripts for which they may have a conflict of interest. The editors and reviewers of this article have no conflicts of interest.

Received for publication June 4, 2020; revisions received June 4, 2020; accepted for publication June 6, 2020; available ahead of print June 14, 2020.

Address for reprints: Vito Domenico Bruno, MD, PhD, Bristol Medical School Translational Health Sciences, University of Bristol, Research Floor Level 7, Bristol Royal Infirmary, Upper Maudlin St, BS2 8HW Bristol, United Kingdom (E-mail: Vito.D.Bruno@bristol.ac.uk).

JTCVS Techniques 2020;3:122-3

2666-2507

Copyright (c) 2020 The Authors. Published by Elsevier Inc. on behalf of The American Association for Thoracic Surgery. This is an open access article under the CC BY-NCND license (http://creativecommons.org/licenses/by-nc-nd/4.0/).

https://doi.org/10.1016/j.xjtc.2020.06.001

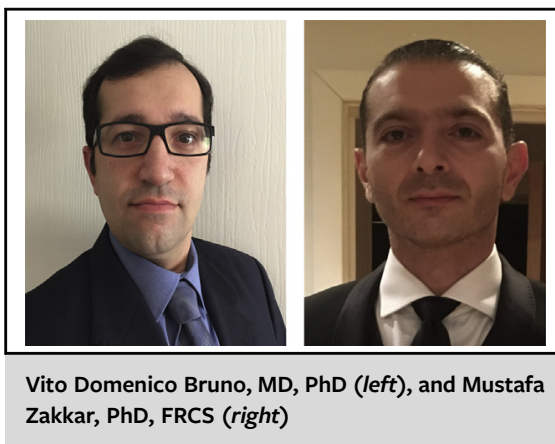

CENTRAL MESSAGE

The loop technique is an effec-

tive and reliable mitral valve

repair technique. Is there a way

to make it even better?

and bileaflet prolapse, different etiologies of MV disease, different surgical approaches, and multiple concomitant procedures: it appears that the authors have found the ideal technique to repair MV. Indeed, the follow-up data show that long-term recurrence of mitral regurgitation was a rare event, with an incidence of $19.8 \%$ at 10 years, with no significant differences between the type of mitral valve lesions or the need of additional repair.

One important finding is related to the incidence of need of a second cardioplegic arrest, which occurred in $10 \%$ of the patients: this was related to misalignment of the MV height requiring loop adjustment or additional neochordal repair. Although the authors have not found a significant correlation with the ink-dot marking test, they recognize that lack of adjustment in patients with irregular height of leaflet by the ink-dot marking test might increase the need for a second cardioplegic arrest. The importance of a correct measurement of the artificial chordae length and leaflet height should be never underestimated, ${ }^{5}$ and Morisaki and colleagues have shown that every detail counts to accomplish an effective MV repair.

Another important intraoperative result to note is the incidence of systolic anterior motion, which was found in $11.7 \%$ of the patients: could this be related to this specific technique? The study has limitations, mostly related to the retrospective nature and the confounding effect of different approaches, but surely represent a step forward in the progressive advancement of the loop technique. Moreover, the presence of several different etiologies is an important confounder and probably for the sake of reproducibility, it would have better to focus on degenerative disease only 
but at the same time the study demonstrate that this technique can be used in different types of diseases. The inkdot marking test seems to significantly help the intraoperative evaluation of the MV repair, therefore providing a more reliable and durable repair.

\section{References}

1. Morisaki A, Takakashi Y, Fujii H, Sakon Y, Murakami T, Shibata T. Loop technique with ink-dot marking test: an alternative strategy to the ink test. J Thorac Cardiovasc Surg Tech. 2020;3:110-21.
2. von Oppell UO, Mohr FW. Chordal replacement for both minimally invasive and conventional mitral valve surgery using premeasured Gore-Tex loops. Ann Thorac Surg. 2000;70:2166-8.

3. Shibata T, Kato Y, Motoki M, Takahashi Y, Morisaki A, Nishimura S, et al. Mitral valve repair with loop technique via median sternotomy in 180 patients. Eur J Cardiothorac Surg. 2015;47:491-6.

4. Anyanwu AC, Adams DH. The intraoperative "ink test": a novel assessment tool in mitral valve repair. J Thorac Cardiovasc Surg. 2007;133: 1635-6.

5. Moorjani N, Viola N, Janusauskas V, Livesey S. Adjusting the length of artificial polytetrafluoroethylene chordae in mitral valve repair by a single loop technique. $J$ Thorac Cardiovasc Surg. 2009;138:1441-2. 